\title{
Niebla de Unamuno más allá de Kierkegaard. Amor y polifonía como superación del naturalismo
}

\author{
Unamuno's Mist Beyond Kierkegaard. \\ Love and Polyphony as an Overcoming of Naturalism
}

Carlos Gardeazábal Bravo ${ }^{12}$

\section{Resumen}

En este ensayo busco señalar algunos puntos que sirven para entender la relación intelectual entre Unamuno y Kierkegaard, especialmente en el contexto de Niebla, a partir de la idea del amor desarrollada por ambos autores. Lecturas mejor fundamentadas de esas similitudes deben apoyarse en una comprensión de los seudónimos y su importancia en la obra de Kierkegaard, junto a la idea de la "comunicación indirecta". Propongo tres puntos de análisis para afinar las comparaciones entre Unamuno y Kierkegaard: 1) Un marco teórico que retome el carácter dialógico de la obra de ambos autores; 2 ) tener en cuenta el contexto intelectual del que surgió Niebla, incluyendo la oposición de Unamuno al naturalismo realista y 3) una lectura rigurosa de Unamuno y Kierkegaard que respete las características especiales de sus obras. A lo largo del ensayo evidenciaré la importancia de la idea de polifonía en ambos autores, particularmente en el Unamuno de Niebla. Sostengo que los puntos de contacto entre Kierkegaard y Unamuno, aunque numerosos, en el fondo pueden ocultar ideas del amor diferentes, especialmente si se tiene en cuenta la línea de interpretación de la "comunicación indirecta".

\section{Palabras clave}

Unamuno, Niebla, Kierkegaard, amor, existencialismo, ética.

\section{Abstract}

In this essay I seek to highlight some insights that help to shed light on the intellectual relation between Unamuno and Kierkegaard, especially in the context of Mist, based on the idea of love developed by both authors. Better supported readings of these similarities are based on an understanding of the importance of the pseudonyms in the work of Kierkegaard and the idea of "indirect communication". I advance three points of analysis to refine the comparisons between Unamuno and Kierkegaard: 1. A theoretical framework that considers the dialogic nature of the work of both authors, 2. take into account the intellectual context in which Mist emerged, including the opposition of Unamuno to realistic naturalism, and 3. a rigorous reading of Unamuno and Kierkegaard that respects the specific characteristics of their works. Throughout the paper I will make clear the importance of the idea of polyphony in both authors, particularly in Unamuno's Mist. I argue that the points of contact between Kierkegaard and Unamuno, although numerous, deep down can hide different concepts of love, especially when taking into account the line of interpretation of "indirect communication".

\section{Keywords}

Unamuno, Kierkegaard, Love, Existentialism, Ethics.

Artículo recibido el 31 de marzo de 2013 y aprobado el 7 de febrero de 2014

1 A la memoria de mi madre, Lucía. A Fátima por el amor auténtico.

2 Universidad de Connecticut: carlos.gardeazabal_bravo@uconn.edu 
Universidad Pedagógica Nacional

Facultad de Humanidades

Niebla de Unamuno es un ejemplo representativo del modernismo español como reacción estética al naturalismo. Unamuno reafirma una visión existencialista en Niebla oponiéndola a la visión proveniente del realismo literario, una estética apoyada en el positivismo de mediados del siglo xIx. La complejidad de la obra se vincula con dicha afirmación del existencialismo, alimentada particularmente por las ideas de Søren Kierkegaard, en un diálogo que incluye las voces de otros pensadores y autores. Los problemas centrales del existencialismo desbordan las restricciones de la descripción naturalista del mundo, centrada en problemas epistemológicos abordados desde un empirismo radical. Unamuno logra una novela que supera en muchos niveles esas limitaciones del naturalismo español gracias a lo que M. Bajtín denominaría polifonía o dialogismo.

En este ensayo busco señalar algunos puntos que sirven para entender la relación intelectual entre Unamuno y Kierkegaard, especialmente en el contexto de Niebla, a partir de la idea del amor desarrollada por ambos autores. Los análisis más sólidos de las similitudes entre estos autores, como los trabajos de R. Webber y J. Evans, tienen en cuenta la importancia de los seudónimos y la comunicación indirecta, instrumentos retóricos clave en la obra de Kierkegaard, haciendo sus conclusiones mucho más fuertes. Propongo aquí, entonces, tres puntos de análisis para afinar las comparaciones entre Unamuno y Kierkegaard: 1) Una perspectiva teórica que retome el carácter dialógico de la obra de ambos autores; 2) tener en cuenta el contexto intelectual del que surgió Niebla, incluyendo la oposición de Unamuno al naturalismo realista y 3) una lectura rigurosa de Unamuno y Kierkegaard que respete las características especiales de sus obras.

Usando el marco teórico provisto por M. Bajtín, a lo largo del ensayo evidenciaré la importancia de la idea de polifonía en ambos autores, particularmente en el Unamuno de Niebla. En oposición a autores como J. A. Ardila, sostengo que los puntos de contacto entre Kierkegaard y Unamuno, aunque numerosos, en el fondo pueden ocultar ideas del amor diferentes, especialmente si se tiene en cuenta la línea de interpretación de la "comunicación indirecta", con lo cual Las obras del amor de Kierkegaard resulta mucho más relevante que sus novelas. Este contrapunto entre ambos autores ayuda a explicar el trasfondo teórico de su oposición al naturalismo, además de algunos detalles de la estructura conceptual de Niebla.

\section{Polifonía y dialogismo en Niebla}

Bajtín desarrolla los conceptos de polifonía y dialogismo en Problemas de la poética de Dostoievski, estableciendo una metáfora que compara estructuras musicales complejas con la estructura de la novela moderna. Bajtín encuentra en la obra de Dostoievski múltiples voces, las cuales lejos de ser fundidas en una sola perspectiva se mantienen independientes de la perspectiva del autor, en un patrón que podemos encontrar en otras novelas polifónicas modernas. En estas novelas cada una de estas voces tiene su propia perspectiva, su propia validez y su propio peso narrativo. ${ }^{3}$

Bajtín afirma que Dostoievsky, y con él la novela moderna polifónica, propone un principio dialógico que se contrapone a las construcciones homófonas o monológicas, constituidas por una sola voz y un solo discurso o visión del mundo. En el discurso monológico una sola perspectiva se ocupa de describirlo todo, organizando a otros discursos como relevantes o superfluos. En este caso las otras voces de la novela adquieren valor únicamente en relación a la perspectiva monológica y por ende terminan siendo reducidos a objetos. El monologismo cierra el mundo que quiere representar, presentándolo como una entidad única y terminada en la que se cierra la posibilidad de otras perspectivas.

Para Bajtín, el autor no ubica su propia visión narrativa entre los personajes y él mismo en la novela polifónica, y en cambio permite que los personajes tengan contrapunteos, conflictos y alianzas ideológicas. La novela adquiere múltiples perspectivas, en lugar de mantener únicamente la perspectiva

3 Los estudios de Wellek (1980), Huerta Calvo (1982) y Holquist (2005) aclaran estos y otros aspectos del concepto de polifonía en Bajtín. 
del autor, o una sola perspectiva privilegiada que quiera describir el mundo tal como es. Polifonía y dialogismo se oponen en Bajtín al naturalismo más básico, el cual busca describir una sola realidad desde solo un punto de vista privilegiado ${ }^{4}$.

La novela surge como una interacción de diferentes ideologías y perspectivas, encarnadas y vividas por los diferentes personajes. Los personajes, por lo tanto, son capaces de hablar y actuar por sí mismos, incluso contra el autor, como en el caso de Augusto Pérez en Niebla. El papel del autor cambia, dado que ya no puede concentrar todo el poder. Bajtín afirma que el autor "no crea esclavos carentes de voz propia (como lo hace Zeus), sino personas libres, capaces de enfrentarse a su creador; de no estar de acuerdo con él y hasta de oponérsele" (Bajtín, 2003, p. 14). Bajtín no llega, sin embargo, a asumir posiciones radicales en las que la voz del autor es completamente anulada. Unamuno se refiere a este punto en este pasaje de Niebla: "[...] empezarás creyendo que los llevas tú, de tu mano, y es fácil que acabes convenciéndote de que son ellos los que te llevan. Es muy frecuente que un autor acabe por ser juguete de sus ficciones [...]" (p. 200).

Las características dialógicas de la novela polifónica, marco propicio para la pluralidad de voces conceptuales, serán potenciadas en Niebla permitiendo el intercambio dentro de su novela entre diversas voces, como demuestran algunos críticos que han enfatizado en la faceta dialógica de la novela de Unamuno. Kierkegaard hará algo similar a lo largo de su obra, en donde las voces de sus diferentes seudónimos proveerán interesantes matices a sus argumentos, a lo cual me referiré en la sección 3.

Iris Zavala en Unamuno y el pensamiento dialógico desarrolla la relación entre Bajtín y Unamuno y el concepto de dialogicidad, especialmente en Niebla y sus obras de teatro, a través de una lectura nietzs-

4 Dice Bajtín en Problemas de la poética de Dostoievski: “El discurso del héroe acerca del mundo y de sí mismo es autónomo como el discurso normal del autor; no aparece sometido a su imagen objetivada como una de sus características, pero tampoco es portavoz del autor tiene una excepcional independencia en la estructura, parece sonar al lado del autor y combina de una manera especial con éste y con las voces igualmente independientes de otros héroes" (2003, p. 15). cheana de ambos autores. Zavala parte de la idea bajtiniana de existencia como diálogo y del yo como signo, para pasar luego a la autocreación del yo, la creación literaria y la existencia como creación en la obra de Unamuno (1991, p. 14). Zavala defiende al dialogismo como la designación más apropiada para las preocupaciones epistemológicas de Unamuno, lo que permite explicar los aspectos más importantes de su obra, incluyendo su carácter abierto, lejano a las síntesis de elementos contrarios. Para Zavala lo dialógico "indica una suerte de revolución permanente, sin mecanismos de poder, en posiciones diferenciales que revelan simultáneamente dispersiones del sujeto, relaciones de enunciados (propios y ajenos) en coexistencia" (1991, p. 34-35). Mi lectura de Unamuno retoma en parte las ideas de Zavala, complementándolas con las posiciones de otros intérpretes de su faceta dialógica y polifónica.

Tal como señala Orringer en su reseña del libro de Zavala, el aspecto dialógico de la obra de Unamuno ha sido subrayado en diferentes ocasiones por sus críticos, quienes han encontrado indicios importantes de diálogos de carácter espiritual, metafísico o estético entre las voces que aparecen en sus novelas. En Unamuno y Dios Enrique Rivera de Ventosa sostiene que, de una forma similar a Kierkegaard, Unamuno parece iniciar un diálogo con Dios que acaba siendo un tipo particular de monólogo. Paul Hie en su Unamuno. An Existential View of Self and Society (p. 54-56) destaca el "monodiálogo", el discurso interno de un yo fragmentado usado por Unamuno, diferenciándolo del monólogo y el diálogo.

El carácter polifónico de la obra de Unamuno permite que aparezcan en Niebla numerosas voces y redes intertextuales, contrapuntos con otras obras y posiciones intelectuales. Entre esas voces aparecen La Celestina y El Quijote, cuyas relaciones con Niebla han sido objeto de numerosos análisis (Ardila, 2010; Vauthier, 1999). El uso del sueño como recurso escéptico en oposición al naturalismo establece conexiones entre Niebla y La vida es sueño de Calderón, Hamlet de Shakespeare y clásicos griegos como Píndaro (Zavala, 1991; Quinziano, 1998). 
Universidad Pedagógica Nacional

Facultad de Humanidades

Su adopción de estrategias antidogmáticas cercanas al escepticismo, incluyendo al recurso del sueño, establece diálogos con otras voces pirrónicas como la obra de Montaigne, Sexto Empírico y Diógenes Laercio, con lo cual, en contraste con el escepticismo racionalista de Descartes, Unamuno cierra la posibilidad a certezas absolutas (Cope, 2009; Bradatan, 2004; Carpio, 1974).

La polifonía de Unamuno en Niebla se opone al naturalismo realista y a su monología excluyente. Las relaciones dialógicas con el existencialismo de Kierkegaard, una de las voces más fuertes de la novela, se opondrán al positivismo subyacente al realismo literario. Las evidencias históricas y literarias que pueden sustentar esta idea las expondré en la siguiente sección, donde relacionaré a Unamuno y Niebla con su contexto intelectual. En la sección 3 profundizaré en la relación entre Niebla y el ideario de Kierkegaard.

\section{Unamuno, la generación del 98 y la reacción contra el naturalismo}

El modernismo español se caracterizó por el rechazo al naturalismo realista. Aunque en España el naturalismo no alcanzó a tener la visión radical de autores como Zola, novelistas como Emilia Pardo Bazán, Blasco Ibáñez o Pérez Galdós adaptaron el realismo naturalista a su estética literaria. Prácticamente un contemporáneo de los naturalistas, Ángel Ganivet describe y analiza el impacto del naturalismo en la literatura española en su España filosófica contemporánea, donde escribe:

Después de algunas escasas muestras de la novela histórica, de la sentimental y de la de costumbres, se ha impuesto la psicológica o analítica tan defendida por Zola [...] La doctrina del fundador de la novísima escuela literaria se condensa en tres afirmaciones: el organismo humano, como todos los demás, se rige por leyes fatales, siendo una especie de máquina cuyo motor es el temperamento, el cual explica la gran variedad de las funciones individuales; para estudiar la vida del hombre, hemos de valernos del método mismo de la ciencia positiva, de la observación y del análisis, ya que el experimento no sea posible; para exponer el resultado de nuestro estudio, nos serviremos del lenguaje más acomodado a la realidad y más apto para expresarla fielmente; desechando el auxilio de la imaginación que es un colaborador pernicioso. Fácilmente se nota que la novela española contemporánea coincide en sus tendencias con estas dos últimas conclusiones, aunque moderándolas prudentemente, pero difiere de la primera por completo. El fondo filosófico de la novela naturalista es un positivismo radical, que no acepta ningún novelista español digno de esta consideración. Alarcón, Pereda, Trueba, Pardo Bazán y la mayor parte de ellos son espiritualistas, Valera, Galdós y otros lo son también, aunque también propenden al escepticismo. (Ganivet, 1930, p 33. El énfasis es mío)

Este pasaje resulta crucial para mis propósitos por dos razones: primero, porque delimita el naturalismo e identifica la forma en que fue adaptado el proyecto naturalista de Zola en España. Segundo, porque hace evidente la conexión entre positivismo y naturalismo para los autores españoles de ese periodo (Longhurst, 1999). El determinismo, el afán por acercarse al lenguaje de la ciencia y su descripción objetiva de una realidad tienen sus raíces en el positivismo, aunque ningún autor español lo haya abrazado plenamente. A pesar de este atenuante, podemos afirmar que si el modernismo español -especialmente el de la generación del 98 e incluyendo a Unamuno- quería rechazar a los seguidores de Zola tenía que oponerse entonces no solo a la versión realista del naturalismo, sino al positivismo que subyacía a su visión del mundo. Por otro lado, la reacción al naturalismo no se dio de manera súbita, ni los autores del realismo fueron repudiados completamente por Unamuno y los demás miembros de la generación del 98 . Puede rastrearse una herencia naturalista en los novelistas del 98, pero lo importante es que estos autores no estaban interesados en seguir esa línea estética ni sus restricciones. El naturalismo no permite novelas polifónicas como Niebla, por ejemplo.

En su rechazo al positivismo vinculado al realismo naturalista, la novela experimental modernista muestra fuertes aspectos discursivos en los 
que la trama, los personajes y la descripción junto a otras características centrales del arte mimético dejan de ser importantes. Roberta Johnson aclara este proceso en Crossfire. Philosophy and the Novel in Spain, 1900-1934 (1993), un estudio bastante útil para entender esta época de transición de la novela española y los combates personales y filosóficos que la caracterizaron. Sus argumentos sustentan la idea de que las novelas de Baroja, Martínez Ruiz y Unamuno son una reacción no solo contra sus predecesores realistas sino contra la filosofía que las apoyaba, producto además de la entrada tardía por parte de España al mundo intelectual europeo de finales del siglo xix y de la crisis creada después de la caída de su Imperio. La novela se convirtió entonces en la mejor forma de explorar conceptos y posiciones contradictorios sin necesidad de comprometerse tajantemente con discursos o corrientes, como sí sucede con el tratado filosófico, casi siempre "ciego hacia sí mismo" (Johnson, 1993, p 5). La novela toma distancia del tratado o el ensayo, que buscan refutar o corregir posiciones existentes, forzando un juicio a favor o en contra de dichas alternativas. Siguiendo a Bajtín, Johnson afirma que la novela puede presentar diferentes posiciones filosóficas sin necesidad de apoyar alguna de manera definitiva (Johnson, 1993, p 6-7).

En la Madrid de Unamuno circulaban diversas corrientes filosóficas dentro de un caótico ambiente intelectual. Unamuno tuvo contacto con estas corrientes, tomando partido en debates intelectuales que ayudarían a moldear su obra. ${ }^{5}$ Estos debates incluían de manera destacada diversas posiciones respecto a la filosofía de la religión, un aspecto muy importante para un autor con profundas preocupaciones espirituales como Unamuno, las cuales tampoco cabían en el proyecto naturalista. Precisamente lo que distinguiría a Unamuno entre este contexto intelectual español sería su cercanía a la teología

5 Según Orringer (2007) entre esas diversas corrientes estaban el neokantismo; el krausismo de Julián Sanz del Río y Joaquín Costa; interpretaciones tardías de Hegel; seguidores del positivismo de $\mathrm{H}$. Spencer; el catolicismo conservador de Marcelino Meléndez Pelayo y el de línea progresista influenciado por Ernest Renán, además de la llamada "teología moderna". Entre algunos grupos políticos se daba ya un incipiente marxismo, sumado a las corrientes anarquistas. protestante (Orringer, 1985), uno de los caminos que le llevaría al existencialismo de Kierkegaard, cuya lectura le permitiría superar las limitaciones conceptuales del ideario de Spencer, Hegel y Krause (Johnson, 1993). En la siguiente sección profundizaré en este punto, incluyendo el concepto de amor en estos autores.

Este fuego cruzado entre posiciones filosóficas sería el contexto intelectual del que surgiría Niebla, una obra que critica tanto al racionalismo vitalista de Ortega y Gasset como al naturalismo, mientras se acerca al existencialismo de Kierkegaard (Johnson, 1993). ${ }^{6}$ El núcleo del existencialismo de Unamuno lo constituirá el lema de Kierkegaard "la verdad es la subjetividad" (Evans, 2011, p. 379), una especie de eslogan polifónico que trabaja silenciosamente a lo largo de Niebla. La forma en que Unamuno incorpora la reflexión existencialista en su obra lleva a Johnson a afirmar que creó un nuevo género, la "novela filosófica representacional", anticipándose a otros autores existencialistas que adaptarían la novela a ese híbrido como Jean Paul Sartre, Albert Camus, y Milan Kundera (Johnson, 1993). Uno de los temas centrales de estas novelas es el amor, abordado desde una perspectiva diferente a la romántica tradicional, como mostraré en la siguiente sección.

\section{Niebla y Kierkegaard. Los trabajos del amor}

En una carta a Clarín de abril de 1900, Unamuno anuncia el comienzo de un productivo proceso intelectual:

Hay en la teología unos tesoros [...] Ahora que traduzco ya el dano-noruego o norso-danés voy a

6 Cabe resaltar que, aunque no fue la única corriente que se le opuso, desde la segunda mitad del siglo XIX el naciente existencialismo confrontó al positivismo y a su racionalismo científico a ultranza. El primer existencialismo propone como centro de la comprensión del mundo a la experiencia subjetiva humana, al contrario de la cientifización utilitarista que defiende el positivismo. El existencialismo temprano, de la mano de Kierkegaard y Nietzsche, propone problemas primordialmente éticos de una forma que evoca la mayéutica socrática, requiriendo una reflexión vital y genuina por parte del lector. La angustia, la alienación y el absurdo se convierten en algunos de los temas centrales de esta visión, abandonando las restricciones de la descripción naturalista del mundo centrada el empirismo radical. 
chapuzarme en el teólogo y pensador Kierkegaard fuente capital de Ibsen, que decía de joven que aspiraba a ser poeta de Kierkegaard, según he leído en el libro de Brandes sobre Ibsen, que es donde empecé a aprender danés (tarea facilísima sabiendo alemán e inglés). ${ }^{7}$

El autor vasco tuvo acceso a las obras completas en danés de Kierkegaard entre 1901 y 1906 y al parecer leyó todos los tomos a excepción de un par de volúmenes, los cuales hacían parte de su notable biblioteca de autores daneses (Evans, 2011, p. 377; Chabrán, 2009, p. 142-145). En palabras de Johnson: "Most importantly Kierkegaard's personalist philosophy, which Unamuno began reading in 1901 and continued to devour through 1906 as new volumes became available, provided him with a substitute for the rationalism and positivism he had discarded" (1991, p. 93). Tal como señalan Evans (2011, p. 375) y Roberts (1986, p. 55), Unamuno no exagera cuando llega a referirse a Kierkegaard como su hermano espiritual en Del sentido trágico de la vida (1913), donde Unamuno señala a Kierkegaard, Pascal y Agustín en el primer capítulo del libro como pensadores con quienes comparte esa cercanía intelectual. En esta sección llevaré a cabo un análisis dialógico de Niebla a partir de Bajtín, mostrando cómo los conceptos de amor de Kierkegaard y Unamuno trabajan en conjunto en esta novela en un contrapunto antinaturalista/positivista, complementando el análisis de Ardila sobre el mismo tema (2008). A pesar de sus numerosos puntos de contacto, concluiré que las visiones sobre el amor de estos autores no son en el fondo tan similares. Antes de ello haré una introducción general a las posiciones de la crítica acerca de las relaciones entre los dos autores.

La interpretación crítica acerca de la relación entre Unamuno y Kierkegaard se centró originalmente en el problema de qué tan profunda fue la

7 Menéndez Pelayo, Unamuno, Palacio Valdés (1941). Epistolario a Clarín, Madrid, Ed. Escorial, p. 74-83. Algunos críticos ven en Unamuno (1864-1936) a un puente generacional entre el existencialismo de Kierkegaard (1813-1855) y el de M. Heidegger (1889-1976) y J. P. Sartre (1905-1980). También podrían establecerse fructíferos vínculos de Unamuno con autores latinoamericanos de línea existencialista como Fernando González, Ernesto Sábato y Juan Carlos Onetti. influencia del danés en Unamuno. ${ }^{8}$ Una línea de interpretación posterior subraya las similitudes entre ambos autores, dándole menos importancia al problema de la influencia y buscando nuevos paralelos e intersecciones entre sus obras. En 1964 Ruth H. Webber publica "Kierkegaard and the Elaboration of Unamuno's Niebla" uno de los primeros estudios en señalar la influencia de $O$ lo uno o lo otro (EntenEller) de Kierkegaard en la estructura de Niebla. Gemma Roberts continúa esta línea de análisis en su Unamuno: afinidades y coincidencias kierkegaardianas en donde confirma la tesis de Webber aunque ampliando el alcance de sus conclusiones. Roberts encuentra en Niebla un diálogo simultáneo con diferentes textos de Kierkegaard, en un riguroso estudio comparativo de ambos autores, centrándose en la influencia de $O$ lo uno o lo otro (la cual contiene al famoso Diario de un seductor) y del Postscriptum definitivo y no cientifico a las migajas filosóficas en la novela de Unamuno. Webber y Roberts se esfuerzan por demostrar que las coincidencias entre ambos autores no convierten a Unamuno en un imitador, ya que este se habría apropiado de las ideas de Kierkegaard de una forma muy personal (Evans, 2005, p. 3).

J. E. Evans plantea una nueva interpretación mediadora entre las posiciones anteriores en su artículo "Unamuno and Kierkegaard: Clarifying the Relationship" y su libro Unamuno and Kierkegaard: Paths to Selfhood in Fiction, basándose en la idea de la "comunicación indirecta", un elemento crucial

8 Ejemplos de esta etapa: François Meyer en La ontología de Miguel de Unamuno (1962) sostiene que Unamuno leyó de una forma superficial a Kierkegaard, y que la influencia en su obra fue mínima, dado que su pensamiento había ya madurado y sus intereses intelectuales ya estaban establecidos para cuando leyó al autor danés. Antonio Sánchez Barbudo (1959, p. 67) también concluye que Unamuno ya tenía mucho de Kierkegaard cuando lo leyó, aunque señala la influencia de Kierkegaard en la crisis espiritual de Unamuno en el 97, entre otros puntos de encuentro, llegando a afirmar que Unamuno lo cita en su obra menos de lo que debería (p. 65). Jesús Antonio Collado publica en 1962 un detallado estudio, Kierkegaard y Unamuno: La existencia religiosa, en el que busca aclarar la influencia del autor danés en Unamuno, centrándose en sus concepciones comunes sobre lo existencial y lo religioso. Este estudio sienta las bases de investigaciones posteriores, estableciendo claramente las intersecciones del pensamiento de ambos autores, aunque concluye que las diferencias entre ellos son mayores que las coincidencias. 
en la interpretación reciente de Kierkegaard. Evans insiste en que las obras de Kierkegaard deben ser estudiadas teniendo en cuenta la división entre las que fueron publicadas bajo otros seudónimos y las que firmó Kierkegaard como suyas, siguiendo las directrices que había expresado claramente el autor mismo. En esta interpretación, dentro de las obras escritas bajo otros seudónimos numerosos términos clave pueden acabar teniendo valoraciones de significado diferentes (Evans, 2005). Creo que esta línea de interpretación es muy importante para aclarar las relaciones entre los dos autores.

Dado que su propósito era vincular lo personal con lo filosófico, el arsenal retórico de Kierkegaard se alejaba de los tratados filosóficos tradicionales acercándose al mismo tiempo al método socrático. Para este propósito incluía ironía, parodia y humor en sus trabajos, sumando a estos recursos el método dialéctico de la "comunicación indirecta" con el propósito de lograr una apasionada vinculación del lector en problemas existenciales, buscando que el lector los relacionara con su propia experiencia (Turnbull, 2009). La autoridad del autor puede verse incluso disminuida con este propósito, de manera que cualquier "verdad" que surja de la lectura de sus obras no sea obtenida por vías tradicionalmente objetivas. La "comunicación indirecta" permite expresar a Kierkegaard mediante sus seudónimos aquellos asuntos existenciales que no podrían ser abordados directamente en novelas, ensayos o tratados filosóficos enunciados directamente por él. Kierkegaard afirma bajo uno de sus seudónimos en el Post-scriptum definitivo que la interioridad no puede ser comunicada directamente porque expresarla directamente es externalidad, ya orientada hacia el exterior, no hacia el interior (Kierkegaard, 1992, p. 260). El método de Kierkegaard a todas luces se opone al positivismo, al realismo y a su obsesión con la objetividad, buscando un discurso que estratégicamente evita las intervenciones invasivas (Caputo, 2008).

Siguiendo un método que puede ser explicado directamente con la polifonía bajtiniana, cada voz expresará diferentes posiciones en la obra de
Kierkegaard, buscando distintas reacciones en el lector, lo cual debe ser tenido en cuenta a la hora de interpretar los paralelos con Unamuno, incluyendo posibles errores de interpretación del autor vasco, quien no leyó al autor danés teniendo en cuenta esas voces. Unamuno no leyó Mi punto de vista, por ejemplo, un trabajo en el que Kierkegaard explica abiertamente el uso de la comunicación indirecta y su relación con la adopción de diferentes seudónimos. Al menos dos libros que Kierkegaard escribió bajo seudónimos como $O$ lo uno o lo otro y el Post-scriptum definitivo tuvieron gran repercusión en Unamuno, pero ni el autor vasco ni la mayoría de sus críticos los interpretó teniendo en cuenta la estrategia indirecta del danés (Evans, 2003, p. 308).

Un ejemplo de la interpretación de ambos autores que no tiene en cuenta la importancia de los seudónimos ni la vía de la interpretación de la comunicación indirecta lo encontramos en "Nueva lectura de Niebla: Kierkegaard y el amor" de J. A. G. Ardila. En este artículo, Ardila retoma el análisis de Webber sobre las semejanzas entre O lo uno o lo otro, el Diario de un seductor y Niebla, aclarando la importancia del concepto de amor compartido por estas novelas y sus autores y la influencia de otra obra de Unamuno en su propia novela: Del sentimiento trágico de la vida. El amor, concluye Ardila luego de una rigurosa comparación de los textos, vendría a ser el principio ontológico de Niebla, gracias en parte al influjo de Kierkegaard: los puntos de contacto entre Niebla y el Diario de un seductor son numerosos, pero hay uno en particular que subraya Ardila, los protagonistas de ambas novelas, Johannes y Augusto, pretenden alcanzar por medio de la razón "el valor más absoluto de la existencia, que es lo que ambos autores denominan amor sentimental o espiritual". Por otro lado, ambos autores y sus novelas coinciden en que "el amor es lo único que puede trascender la muerte, esto es, que el amor es el todo y el desamor (o la ausencia del sentimiento amoroso) es la nada." Especialmente en el caso de Niebla "el amor espiritual confiere sentido a la existencia" (2008, p. 113). 
Universidad Pedagógica Nacional

Facultad de Humanidades

Aunque sus comparaciones están bien fundamentadas, la interpretación de Ardila resulta incompleta al no tener en cuenta el problema que crea la "comunicación indirecta" y el uso de seudónimos para interpretar a Kierkegaard. Ardila dice complementar el trabajo de Webber pero no continúa uno de los numerosos aciertos de esta autora: en su artículo Webber se cuida de no atribuir a Kierkegaard las ideas que sostienen sus personajes en $O$ lo uno o lo otro y Diario de un seductor, llegando incluso a citar la explicación del Post-scriptum definitivo en el que se explica la individualidad poética de los seudónimos y la petición que hace Kierkegaard de no atribuirle esas posiciones. Webber concluye que esta estrategia narrativa de Kierkegaard es un precedente de Víctor Goti, el personaje-prologuista de Niebla, y de la idea de la independencia de los personajes que atraviesa la obra de Unamuno (Webber, 1964, p. 134). Aunque Webber no tiene en cuenta que Unamuno muy probablemente no leyó el Postscriptum, como señala J. E. Evans (2005, p. 21), al menos su conclusión se apoya en una comprensión razonable de los seudónimos y su importancia en la obra de Kierkegaard. Este tipo de consideración no aparece en los argumentos de Ardila.

Dado el contexto cultural que describe detalladamente Johnson, al que me referí en la sección 2, el contacto de Unamuno con la teología protestante fue muy importante, siendo este uno de los probables motivos de su acercamiento a Kierkegaard, además de su interés por la obra de Ibsen. Tal como señala J. E. Evans (2003, p 308), Unamuno también estudió con cuidado las obras específicamente religiosas del autor danés, en particular Las obras del amor, un trabajo central para entender la teoría del amor que ofrecía Kierkegaard y que además puso bajo su autoría. Ardila no tiene en cuenta este trabajo a pesar de que afirma que ambos autores concluyen que el amor es el principio ontológico principal. Aunque encuentra una interesante y productiva conexión entre Niebla y Del sentido trágico de la vida, en donde Unamuno expone su idea del amor, Ardila no tiene en cuenta una versión anterior de ese texto que Unamuno dedicó enteramente a ese tema, el Tratado del amor de Dios, publicado pós- tumamente y escrito entre 1905 y 1908, en donde el carácter modernista de sus reflexiones religiosas lo habría puesto en conflicto con la Iglesia católica (Tedeschi, 2008, p. 76; Orringer, 2007, p. xxxiv). Ambas obras, Tratado del amor de Dios y Las obras del amor, encajan directamente con el tema del amor en Niebla, incluyendo el amor espiritual y el ágape, el amor espiritual no romántico privilegiado por ambos autores.

Sobre la importancia del ágape en el autor vasco, Orringer (1987) ha enfatizado en la influencia de Platón en la obra de Unamuno en general. En efecto, podemos rastrear esta influencia ya sea como referente dialógico o como blanco de sus críticas, incluyendo la idea de amor que presenta en sus obras. Esta relación me ayudará a esbozar los puntos de contacto de Las obras del amor de Kierkegaard en Niebla, en particular la relevancia del ágape en ellas. Creo que este pasaje de la novela de Unamuno es central para ese propósito:

- Pues eso es, querido Augusto, que tu repuesto de amor dormía inerte en el fondo de tu alma sin tener dónde verterse; llegó Eugenia, la pianista, te sacudió y remejió con sus ojos esa charca en que tu amor dormía: se despertó éste, brotó de ella, y como es tan grande se extiende a todas partes. Cuando uno como tú se enamora de veras de una mujer, se enamora a la vez de todas las demás [...] Tú estabas enamorado, sin saberlo por supuesto, de la mujer, del abstracto, no de esta ni de aquella; al ver a Eugenia, ese abstracto se concretó y la mujer se hizo una mujer y te enamoraste de ella, y ahora vas de ella, sin dejarla, a casi todas las mujeres, $y$ te enamoras de la colectividad, del género. Has pasado, pues, de lo abstracto a lo concreto y de lo concreto a lo genérico, de la mujer a una mujer y de una mujer a las mujeres.

— ¡Vaya una metafísica!

-Y ¿qué es el amor sino metafísica? (Unamuno, 2010, p. 156-157 El énfasis es mío)

Lo que Víctor Goti diagnostica aquí a Augusto Pérez es similar a lo que Diotima, una de las voces del diálogo El banquete de Platón, le dice a Sócrates 
que debe darse con todo aquel que continúe el método apropiado en el amor:

[...] empezando por las cosas bellas de aquí y sirviéndose de ellas como de peldaños ir ascendiendo continuamente, en base a aquella belleza, de uno solo a dos y de dos a todos los cuerpos bellos y de los cuerpos bellos a las bellas normas de conducta, y de las normas de conducta a los bellos conocimientos, y partiendo de estos terminar en aquel conocimiento que es conocimiento sino de aquella belleza absoluta, para que conozca al fin lo que es la belleza en sí. (Platón, 1992, p. 264 [211c])

Esta escala ha sido el referente principal de las teorías intelectualistas del amor, para las cuales el amor es una forma de llegar al conocimiento más preciado, en este caso la idea de la belleza, y en las cuales el amor por los entes particulares tiene apenas una mínima validez. En otro punto, Víctor Goti llega a proponerle a Augusto una especie de innatismo platónico para explicar su amor por Eugenia: "Naturalmente, tú estás enamorado ab origine, desde que naciste; tienes un amorío innato" (Unamuno, 2010, p. 121).

Gracias a la polifonía bajtiniana podemos diferenciar las voces de los personajes, especialmente la de Víctor Goti, de la del autor. Aunque Víctor apoya la visión platónica del amor en Niebla, hay suficiente evidencia para mostrar que Unamuno no la apoya y que Niebla como un todo funciona como soporte de su argumento. El amor guiado por la abstracción despersonificada que describe Víctor lleva a un callejón existencial sin salida. Tal como señala Orringer (1987, p. 335), Augusto Pérez sigue a lo largo de la novela la idea descrita por Víctor, la voz platónica, con resultados desastrosos en su vida amorosa, llena de reflexiones teóricas y vacía de acción, de carne. Augusto sigue esta línea del amor platónico hasta el extremo, aplicando incluso a su vida amorosa la idea de la división del alma vinculada a la razón, el corazón y los apetitos - la cual defiende Platón en La república-: después de su entrevista con Paparrigópulos - la voz científica-positivistaAugusto lleva a cabo un experimento sobre psicología femenina con las tres mujeres, y cada una apunta a una de sus facultades: Eugenia a su cabeza, su lavandera Rosario a su corazón y Liduvina, su cocinera, a su estómago (Unamuno, 2010, p. 243). En el capítulo VII Augusto había afirmado, en una significativa parodia de Descartes, Amo, ergo sum, mientras piensa en su amor por Eugenia (Unamuno, 2010, p. 141). Este amor teórico hace que el sentimiento y la acción sean completamente dependientes de la razón y la reflexión por sí mismas, creando un vacío en el cual Augusto queda inmovilizado, absorto. Augusto le dice en medio de un sueño a Unamuno en "Una entrevista con Augusto Pérez" que "me afirmé muriendo" (Unamuno, 2010, p. 79). En una paradoja trágica, Augusto actúa apasionadamente por primera vez al escoger su propia muerte, abandonando la vía abstracta e intelectual expuesta por Víctor (Evans, 2005, p. 81).

Siguiendo esta línea argumentativa, Orringer también sostiene que Unamuno buscó alejarse de las visiones intelectualistas del amor, incluyendo la clásica teoría platónica. Confirmando su oposición a esas visiones intelectualistas, en Del sentimiento trágico de la vida Unamuno hace una escala similar a la platónica, pero haciendo cambios en los elementos involucrados: "De amar los bienes, pasamos a amar el Bien; de las cosas bellas, a la Belleza; de lo verdadero, a la Verdad; de amar los goces, a amar la Felicidad, y, por último, a amar al Amor" (1983, p. 237). El ascenso lleva a lo verdadero, a la felicidad, y finalmente al amor en sí mismo; no es ya el conocimiento el objetivo principal del proceso. De hecho en Del sentimiento (1983, p. 80), Unamuno afirma que el amor en su forma más básica precede al conocimiento, tal como Augusto sostiene en uno de sus muchos monólogos interiores "el amor precede al conocimiento, y este mata a aquel" (2010, p. 123). En otro pasaje Del sentimiento dice Unamuno que "el amor no es en el fondo ni idea ni volición: es más bien deseo, sentimiento; es algo carnal hasta en el espíritu” (1983, p. 180).

La idea del amor que propone Unamuno está ligada todavía al deseo (Frayle Delgado, 1995), no solo al intelecto, y no es netamente abstracta, aunque busque un amor superior, el amor espiritual. 
Universidad Pedagógica Nacional

Facultad de Humanidades

Unamuno pasa del eros, el amor romántico individualista y patológico, al ágape, el amor espiritual, pero lo hace sin necesidad de anular al amor más básico y primordial. Fiel a su visión existencialista, Unamuno afirma en Del sentimiento trágico:

De este amor carnal y primitivo de que vengo hablando, de este amor de todo el cuerpo con sus sentidos, que es el origen animal de la sociedad humana, de este enamoramiento surge el amor espiritual y doloroso. Esta otra forma del amor, este amor espiritual, nace del dolor, nace de la muerte del amor carnal. (1983, p. 182)

Augusto confirma este vínculo entre amor espiritual y el dolor cuando le confiesa a su perro "[...] gracias al amor siento al alma de bulto, la toco. Empieza a dolerme en su cogollo mismo el alma, gracias al amor, Orfeo. Y el alma misma, ¿qué es sino amor, sino dolor encarnado?" (2010, p. 141).

El concepto de amor que Kierkegaard propone en Las obras del amor también confronta a la visión intelectualista platónica, mientras propone una escala en la que encontramos en su estadio superior al ágape o amor espiritual, de manera que el amor romántico que aparece en sus otros trabajos viene a representar los estadios que llevan a ese amor espiritual. Las novelas $O$ lo uno o lo otro, incluyendo al Diario de un seductor o incluso Temor y temblor, todas firmadas por sus seudónimos, servirían además como ejemplos de los diferentes niveles existenciales propuestos por Kierkegaard, el estético, el ético y el religioso (Caputo, 2008, p. 21-56; Hall, 2002, p. 6-9). El amor en Kierkegaard, además, tiene una función ética y ontológica muy importante que lo convierte en un concepto central contra la visión positivista del mundo, en donde la valoración emocional del mundo no tiene importancia. Fiel a los propósitos y al contexto religioso de su reflexión, para Kierkegaard el amor de Dios es la fuente que permite la unión de lo finito y lo infinito (Furtak, 2005). En Las obras del amor Kierkegaard identifica al amor como la fuente de todo (1995, p. 215, 3n), el soporte más profundo de la vida espiritual, que nos provee de razones para actuar y para superar la peor duda escéptica. En una línea similar Unamuno afirma en Del sentimiento que "no se conoce nada que de un modo o de otro no se haya antes querido, y hasta cabe añadir que no se puede conocer bien nada que no se ame, que no se compadezca" (1983, p. 184).

Para Kierkegaard el amor erótico no es necesariamente un tipo de amor espurio, es solo un paso en la escala hacia el ágape, el amor espiritual superior: el amor al prójimo, el cual transforma a todos los otros tipos de amor y que puede coexistir con el eros (2009, p. 156-159). El amor al prójimo que ensalza Kierkegaard tiene una particular faceta que elimina los aspectos preferenciales del amor, lo cual lo convierte en un amor igualitario en extremo: el amor al prójimo no tiene en cuenta las cualidades diferenciadoras de reyes o mendigos, por lo que se convierte en la marca de la eternidad en cada ser humano (Kierkegaard, 1995, p. 89). Como el amor espiritual de Unamuno, este es el amor por sí mismo, pero en este caso ya no se trata de un amor personificado. Este tipo de ágape es completamente indiferente al objeto amado.

Las reflexiones de S. Žižek sobre Kierkegaard en este punto resultan pertinentes: no es casual que el autor danés estuviera obsesionado con Don Juan. El amor cristiano por el prójimo y la seducción en serie de Don Juan comparten una crucial indiferencia por su objeto amoroso. Para Don Juan las cualidades del objeto seducido tampoco importan, lo relevante es el hecho meramente numérico de agregar otro nombre a la lista. En ese sentido Don Juan sería el seductor cristiano por excelencia, dado que sus conquistas son hechas en nombre del amor y por el amor mismo y no por las características contingentes que poseen sus objetos conquistados. El amor cristiano de Kierkegaard quiere borrar las cualidades que definen a cada vecino, como si ya estuviera muerto. Žižek concluye que Kierkegaard quiere vendernos como un difícil acto de amor lo que en realidad es un escape del esfuerzo que implica el amor auténtico (Žižek, 2004, p. 213-214; 2005). Víctor Goti (especialmente en el capítulo $X$ de Niebla) y Kierkegaard llegan a estar de acuerdo respecto a la despersonalización del objeto amado. 
Mientras el ágape de Kierkegaard es completamente indiferente al objeto amado, Unamuno insiste abiertamente en la personificación de lo amado en Del sentimiento $(1983$, p. 186, 244) y de manera indirecta en Niebla, al reducir al absurdo a la teoría platónica del amor, al racionalismo cartesiano y a su excesiva insistencia en la abstracción, ejemplificadas por Víctor y sufridas por Augusto, un personaje que en su indecisión puede definirse como un "pensador puro". Esta es una diferencia crucial entre las ideas de amor defendidas por Kierkegaard y Unamuno.

\section{Conclusiones}

Como nos recuerda Evans, Kierkegaard desde un principio afirma que la única pregunta importante para él es "¿cómo me puedo convertir en un cristiano?" Para Kierkegaard solo hay dos opciones: convertirse o no en un verdadero cristiano. Para Unamuno en cambio siempre hay múltiples posibilidades y ninguna de ellas es privilegiada, a excepción de aquella que opte por darle importancia de manera apasionada a la propia existencia (Evans, 2005, p. 309).

El carácter polifónico de la obra de Unamuno y Kierkegaard puede ser comprendido a cabalidad a partir de la teoría dialógica de la novela de Bajtín. Este diálogo entre diferentes voces en sus obras no se da en el vacío. En el caso de Unamuno, el contexto intelectual del que surgió Niebla estaba directamente relacionado con su oposición al naturalismo realista, tal como muestran R. Johnson y N. Orringer. Dentro de ese ambiente intelectual, uno de los factores que destaca a Unamuno entre los demás escritores de la generación del 98 es su posicionamiento como autor existencialista, incluyendo su estudio de las obras de Kierkegaard. Sin embargo, a la hora de hacer paralelos entre ambos autores es necesario tener en cuenta las particularidades de cada uno. En el caso de Kierkegaard, no se puede pasar por alto la importancia de los seudónimos y de la "comunicación indirecta" a la hora de interpretarlo. Es por eso que el estudio de J. A. Ardila sobre el amor en Niebla queda incompleto, igual que cualquier otro que tampoco tenga en cuenta la forma en que
Kierkegaard escribió y las razones por las que lo hizo. Las diferencias que resultan al comparar las ideas del amor que se dan en Niebla y Las obras del amor de Kierkegaard no son irrelevantes, tal como muestran las consecuencias señaladas por S. Žižek. Los hermanos espirituales pueden llegar a tener diferencias como los hermanos de sangre, incluso diferencias de fondo.

\section{Referencias}

Ardila, J. A. G. (2010). Unamuno y Cervantes: narradores y narración en Niebla. MLN, 125(2), 348-368.

Ardila, J. A. G. (2008). Nueva lectura de Niebla: Kierkegaard y el amor. Revista de literatura, 70(139), 85-118.

Bajtín, M. M., Kriúkova, H. S., y Cazcarra, V. (1989). Teoría y estética de la novela: trabajos de investigación. Madrid: Taurus Ediciones.

Bajtín, M. M., Kriúkova, H. S., y Cazcarra, V. (2003). Problemas de la poética de Dostoievski. México: Fondo de Cultura Económica.

Bajtín, M. M. (1982). Estética de la creación verbal. Madrid, Siglo XXI.

Bajtín, M. M. (1984). Problems of Dostoevsky's Poetics. Minneapolis: Univ. Of Minnesota Press.

Bajtín, M. M. (1992). The dialogic imagination: Four essays [M. Holquist (Ed.)]. Austin: University of Texas Press.

Bradatan, C. (2004). "God is dreaming you": Narrative as Imitatio Dei in Miguel de Unamuno. Janus Head, 7(2), 453-467.

Caputo, J. D. (2008). How to read Kierkegaard. New York: WW Norton \& Co.

Carpio, A. P. (1974). Unamuno, filósofo de la subjetividad. En A. Sánchez-Barbudo (Ed.), Miguel de Unamuno (pp. 123-149). Madrid: Taurus.

Chabrán, R. (2009). Miguel De Unamuno y su biblioteca danesa. Revista de Hispanismo Filosófico, 14, 141-54.

Collado, J. A. (1962). Kierkegaard y Unamuno. Madrid: Editorial Gredos.

Cope, B. (2009). The Hellenic Origins of Unamuno's Skepticism and Niebla's Skeptical Parody of Cartesianism. Hispanic Review, 77(4), 471-493. 
Universidad Pedagógica Nacional

Facultad de Humanidades

Evans, J. E. (2003). Unamuno and Kierkegaard: Clarifying the Relationship. Revista Hispánica Moderna, 56(2), 297-310.

Evans, J. E. (2005). Unamuno and Kierkegaard: paths to selfhood in fiction. Lanham: Lexington Books.

Evans, J. E. (2011). Miguel de Unamuno: Kierkegaard's Spanish "Brother". En J. Stewart (Ed.), Kierkegaard and existentialism. Farnham Surrey: Ashgate.

Evans, C. S. (2006). Kierkegaard's Ethic of Love: Divine Commands and Moral Obligations. Oxford: Oxford University Press.

Delgado, L. F. (1995). El amor en Unamuno y sus contemporáneos (Vol. 166). Caracas: Biblioteca de la Academia Nacional de Historia.

Furtak, R. A. (2005). Wisdom in love: Kierkegaard and the Ancient Quest for Emotional Integrity. Notre Dame: University of Notre Dame Press.

Ganivet, A. (1930). España filosófica contemporánea y otros trabajos [Obras Completas, vol. 9]. Madrid: Librería F. Beltrán y Victoriano Suárez.

Hall, A. L. (2002). Kierkegaard and the Treachery of Love. Cambridge: Cambridge University Press.

Hie, P. (1967). Unamuno. An Existential View of Self and Society. Madison: U. Wisconsin.

Holquist, M. (2002). Dialogism: Bakhtin and his world. London: Routledge.

Huerta Calvo, J. (1982). La teoría literaria de Mijail Bajtín (Apuntes y textos para su introducción en España). Dicenda: Cuadernos de filología hispánica, (1), 143-158.

Johnson, R. (1993). Crossfire: Philosophy and the novel in Spain, 1900-1934. Lexington: University of Kentucky Press.

Kierkegaard, S. (1983). Fear and trembling/repetition: Kierkegaard's writings (vol. 6) [Trans. Edna H. Hong and Howard V. Hong]. : Princeton University Press.

Kierkegaard, S. (1987). Either/Or. Part I \& II [Trans. and ed. Howard and Edna Hong]. Princeton: Princeton University Press.

Kierkegaard, S. (1992) Concluding Unscientific Postscript to "Philosophic Fragments" [Trans. and ed. Howard and Edna Hong]. Princeton: Princeton University Press.

Kierkegaard, S. (1995). Works of Love [Trans. and ed. Howard and Edna Hong]. Princeton: Princeton University Press.
Longhurst, A. (1999). The turn of the novel in Spain. From Realism to Modernism in Spanish Fiction. A Further Range. Studies in Modern Spanish Literature from Galdós to Unamuno, Exeter: University of ExterPress, 1-43.

Meyer, F. (1962). La ontología de Miguel de Unamuno. Madrid: Gredos.

Orringer, N. R. (1985). Unamuno y los protestantes liberales (1912): sobre las fuentes de Del sentimiento trágico de la vida. Madrid: Editorial Gredos.

Orringer, N. R. (1987). Unamuno and Plato: A Study of Marginalia and Influence. Revista Canadiense de Estudios Hispánicos, 331-353.

Orringer, N. R. (1993). Review of "Unamuno y el pensamiento dialógico. M. de Unamuno y M. Bajtin”. Anales de la Literatura Española Contemporánea, 18(1/2), 465-467.

Orringer, N. R. (2007). “Translator’s Introduction”. En Unamuno, Miguel de, Orringer, N. R. Treatise on love of God. Urbana: University of Illinois Press.

Platón (1992). Banquete. Madrid: Gredos.

Quinziano, F. (1998). Niebla: Miguel de Unamuno y el sueño de la nivola. En Atti del XVII Convegno [Associacione Ispanisti Italiani]: Milano 24-25-26 ottobre 1996 (pp. 135-148). Bulzoni Editore.

Rivera de Ventosa, E. (1985). Unamuno y Dios. Madrid: Ediciones Encuentro.

Roberts, G. (1986). Unamuno: Afinidades y coincidencias kierkegaardianas. Boulder: Society for Spanish and Spanish-American Studies.

Sánchez-Barbudo, A. (1959). Estudios sobre Unamuno y Machado. Madrid: Ediciones Guadarrama.

Tedeschi, F. (2008) Del Tratado del amor de Dios a Del sentimiento trágico de la vida: gestación de dos tratados. Cuadernos Cátedra Miguel de Unamuno, 46(2), 71-102.

Turnbull, J. (2009). Kierkegaard, Indirect Communication, and Ambiguity. The Heythrop Journal, 50, 13-22.

Unamuno, M. de. (1983). Del sentimiento trágico de la vida; La agonía del cristianismo. Madrid: Akal.

Unamuno, M. de. (2010). Niebla. Barcelona: Cátedra.

Unamuno, M. de. \& Orringer. N. (2005). Del sentimiento trágico de la vida en los hombres y en los pueblos y Tratado del amor de Dios. Madrid: Tecnos.

Unamuno, M. de. \& Orringer, N. (2007). Treatise on Love of God. Urbana: University of Illinois Press. 
Vauthier, B. (1999). Niebla de Miguel de Unamuno: a favor de Cervantes, en contra de los "cervantófilos." Estudio de narratología estilística. Nueva York: Peter Lang.

Webber, R. H. (1964) Kierkegaard and the Elaboration of Unamuno's Niebla. Hispanic Review, 32, 118-134.

Wellek, R. (1980). Bakhtin's view of Dostoevsky: "Polyphony" and "Carnivalesque". Dostoevsky studies, 1, 31-9.

Zavala, I. M. (1991). Unamuno y el pensamiento dialógico: M. de Unamuno y M. Bajtín, Barcelona: Anthropos.

Žižek, S. (2004). “Afterword: Lenin's Choice.” En V. I. Lenin \& S. Žižek, Revolution at the gates: A selection of writings from February to October 1917. London: Verso.

Žižek, S (2005). Neighbors and Other Monsters: A Plea for Ethical Violence. En S. Zižek, E. L. Santner \& K. Reinhard, The neighbor: Three inquiries in political theology. Chicago: University of Chicago Press. 